\title{
THE NASA ADVANCED SOLAR DYNAMICS TECHNOLOGY PROGRAM
}

Marvin Warshay and Thaddeus S. Mroz

National Aeronautics space Administration Lewis Research Center

Cleveland, Ohio

(216) 433-4000

\section{ABSTRACT}

The NASA Advanced Solar Dynamics Technology Program is aimed at developing power system technology for versatile, advanced, high capacity spacecraft and surface power systems. Future solar dynamic space power systems will have the following general characteristics: few to 100's of kWe, lightweight, efficient, multi-altitudes and orbits, long-lived, reliable, and survivable. Attainment of the goals of the program is to be achieved by pursuing high risk but high payof technologies, namely advanced solar concentrators, heat receivers, power conversion dynamic cycles, and radiators. The paper discusses the NASA Advanced Solar Dynamic Technology Program in terms of mission drivers, goals of each of the system major component technologies, and mutiyear programs, system integration, and current status.

\section{INTRODUCTION}

In the 1960-1974 time frame separate programs were conducted by the NASA Lewis Research Center (LeRC) and the Air Force for the development of solar dynamic space power systems. A 10KWe Solar Dynamic Brayton Space Power System was developed by the NASA Lewis Research Center. The Air Force developed and tested a $15 \mathrm{KWe}$ solar dynamic Rankine space power system, complete with concentrator, heat receiver, power conversion system and waste heat rejection system.

The NASA program included the design and fabrication of a 6.25 meter diameter prototype concentrator and complete elements for a 9.3 meter diameter concentrator, a heat receiver with integral Lithium Fluoride (LiF) thermal energy storage and a closed loop Brayton Power System using a mixture of Xenon-Helium (Xe-He) as the working Fluid. The concentrator was developed in a LeRC in-house program. The surface accuracy was experimentally determined to be $1.8 \mathrm{mrad}$. The receiver was developed under contract by General

Electric in refractory metal construction.
Elements of the heat receiver required testing in vacuum. The tests were run at LeRC using an electric heat source. The design heat transfer requirements to the circulating Xe-He working fluid were verified. The closed loop Brayton power conversion systems (PCS) was developed under contract by the Airesearch Corporation (now Allied Signal). The Brayton PCS was tested in vacuum ( $10^{-\infty}$ torr) for a period of 2700 hours using an electric heat source. This system was further tested at 1 atmosphere for a perlod of 36,300 hours under fully automated conditions. The total test period was 39,000 hours. Design objectives were verified. The testing was terminated in 1974 and development was terminated due to a change in NASA space power priorities, However, the test results demonstrated the feasibility of solar dynamic power systems for space applications.

In the 1970-1984 time frame, development of Solar Dynamic Power systems was conducted only by DOE for terrestrial applications. The DOE program focused on performance, economic competitiveness, design life and terrestrial operating environment.

With the advent of the Space station Program there was a resurgence in the application of solar dynamic power for space. Both the "Organic Rankine Cycle" and the "Brayton Cycle" were evaluated for use on the Space station. The Brayton Cycle was selected as a candidate Solar Dynamic Power System for the space station. A conservative design approach was adopted using state-of-the-art technology for high reliability. The Space Station represents one application for solar dynamic power.

Future NASA, DOD and commercial missions beyond the 1996 time frame will require advanced solar dynamic power systems which are more efficient (greater than 25\%) higher specific power $(20-25 \mathrm{w} / \mathrm{kg})$ and lower volume. The power systems will be designed for manned or unmanned operation, depending on the mission, and may have to be fully deployable, erectable and/or redeployable. Launch requirements of the shuttle or an ELV must be considered and will impact design. Power system applications will include equatorial and polar orbits and altitudes ranging from LEO to GEO. Operational life requirements will range from 5-15 years. Safety and reliability in any application is of primary concern.

U.S. Government work not protected by U.S. copyright. 
To meet these mission requirements, an advanced solar dynamic power system technology development program was initiated at LeRC in 1985. The program is funded by NASA OAST. This is a multi-year program which addresses missions and power requirements and carries out the required critical technology development and technology verification through the component and system level.

\section{PROGRAM DESCRIPTION}

The LeRC Advanced Solar Dynamic (ASD) program is a technology development program. It's objective is the development of advanced power system technology which will be needed for future space missions beyond 1996. The ASD program is being carried out for applications requiring versatile high capacity spacecraft and surface power systems (Mars/Lunar). These 1-100 KWe class power systems will be characterized by lightweight, high efficiency, multiorbit operation, long-life, high reliability and survivability. As a result high risk but high payoff concepts are considered and evaluated.

Five basic program elements are incorporated in the ASD program:

1. Mission and Systems Analys is

2. Advanced Concentrator Technology

3. Advanced Heat Receiver Technology

4. Power Conversion Subsystems and Heat Transport/Rejection

5. Micro-gravity and Space Environment Effects

Potential mission applications for Solar Dynamic Power are constantly being identified to answer the question "Where is solar power feasible, 1 .e. where can it be used?" ongoing in-house systems analysis studies evaluate and compare system options and identify advanced technology requirements at the component subsystem and system levels to maintain solar dynamic power competitive with other advanced power systems. In other words, systems studies provide direction to the program.

The initial focus of the program is on the leastdeveloped of the technologies of the ASD program, namely the Solar Concentrator and the Heat Receiver with thermal energy storage.

The Stirling and Brayton Thermal Power Conversion Subsystems are both contenders for solar dynamic power applications. Development of the technology for these PCS's and their Heat Transport/Heat Rejection systems are not being carried out as part of the ASD program. However, technology development for all but the Brayton PCS is being carried out in the same LeRC division (Power Technology) as is the ASD program. Hence, there is close coordination on satisfying the various technology requirements of the ASD components.

The effects of micro gravity on thermal energy storage and space environment on concentrator materials are addressed analytically and experimentally in separate efforts. The micro gravity effort includes a space experiment to validate a very comprehensive computer code which predicts freeze-thaw behavior of thermal energy storage materials at micro-gravity.
Program goals were identified from the results of system studies at the component and system levels: Systems Specific power

Concentrator Specific Weight

Concentrator Accuracy

PCS Efficiency

Design Life

$1-15$ years

Survivability In-space Environment

Operational Temperature

$\begin{array}{ll}\text { Stirling } & 1050-1400 \mathrm{~K} \\ \text { Brayton } & 1100-1400 \mathrm{~K}\end{array}$

The system studies identified ASD power as an attractive alternative to $\mathrm{PV}$ and Nuclear Power. From these studies it was noted that ASD and advanced PV are competing technologies. To be competitive with advanced PV technology, ASD technology development requires

0 Mass reduction by a factor of 2 over state-of-the-art (SOA).

0 Size reduction

o Cost reduction

0 Increase inefficiency over SOA

The ASD program is focused in this direction.

\section{APPROACH}

To meet and implement the objectives and achieve the goals of this program an orderly approach was adopted. The overall program approach incorporates six phases, shown in figure 1.

In this approach the program is initiated with mission and system analysis and proceeds through screening of advanced concepts, concept selection, concept technical feasibility assessment, technology development and technology verification at the component, subsystem and system level.

The ASD program was initiated in 1984 with a contracted "Systems and Definition Study" which identified power system requirements for future NASA, DOD, and commercial missions beyond the 1996 time frame. The mission spectrum included equatorial and polar orbits and altitudes from LEO to GEO. In this study, candidate stirling, Brayton and Rankine cycle power systems were evaluated and selected for representative $7 \mathrm{kWe}$ and $35 \mathrm{kWe}$ missions. Results of this evaluation were further compared with photovoltaic power systems for the same mission requirements. Specific power, weight and size were computed for each power system and used in the comparisons. The study recommended a technology development program. Program goals were identified from the results of analytical system design studies which were conducted in-house evaluating the stirling and Brayton power systems through an output power level range of $1-100 \mathrm{kWe}$, identifying component, subsystem and system performance, specific power, weight and size.

The results provided trends and the effects of PCS inlet temperature, temperature ratio and concentrator accuracy on system specific power, mass and PCS efficiency. This is illustrated on figures $2,3,4$, and figure 5 . This directed the 
effort towards mass reduction at the component level, the need for high accuracy concentrators and power conversion subsystems (Stirling/Brayton) with higher efficiencies. The output of these studies provided the basis for advanced concentrator and heat receiver conceptual design contracted screening studies. It was obvious that the thermal energy storage and containment materials for the heat recejver would pose a formidable challenge, considering higher operating temperatures. As part of the analytical effort, concentrator computer codes were developed by NASA/LeRC and JPL and used for sizing and performance inputs. A comprehensive heat receiver code was developed for LeRC by JPL to provide a modelling and design capability for advanced heat receivers. A code also was developed under a Lewis grant by the University of Southern Florida to model the thermal performance of the heat receiver with thermal energy storage. Existing codes were used to model the PCS (Stirling and Brayton) and the radiator.

\section{Concentrator}

In the concentrator technology development a number of concentrator concepts were evaluated under contract and grant as part of the screening process. This included the "Fresnel Lens" and the "Reflecting" type concentrators. Deployable (including antenna technology) and fixed dish concentrator concepts were proposed. The type of launch vehicle, e. g. Orbiter or an ELV, determines what type of concentrator can be used. The evaluations considered high efficiency, high optical accuracy, fabrication techniques and materials for space compatibility.

One concentrator concept has progressed to the technology feasibility assessment phase of the ASD program. This concept is a fully deployable advanced concentrator. This technology development is being conducted by the Advanced Manufacturing Center of the Cleveland State University. Other conceptual designs, generated under several LeRC industrial contracts, are also being considered for further technology development.

A significant supporting technology effort, both in-house and on contract, is being carried out in the solar concentrator area. To meet the goal of low specific weight and high optical accuracy, development of new fabrication techniques was initiated in-house and under contract for the concentrator substrate and optical surfaces. This effort investigated metallic foam and honeycomb substrates and micro-sheet glass, polymer leveling techniques and Sol-Gel for the optical surface. A new in-house advanced concentrator laboratory is being finalized for the development and evaluation of new fabrication techniques and high accuracy optical surfaces. Effect of space environment (U.V., atomic oxygen, micrometeroids, space debris, plasma etc.) on material selection will be investigated and determined in this program.

Experimental verification of developed technology under space simulated conditions is planned.

Heat Receivers

The approach taken for advanced heat receiver technology development investigates cavity heat pipe designs for uniform cavity temperature distribution, use of thermal energy storage materials with high thermal conductivity and high density to reduce mass and size, and the use of bulk thermal energy storage modules as opposed to small elements. Critical technology identified with advanced heat receivers includes:

o Materials compatibility

0 Uneven flux distribution

0 Advanced heat pipe heat receiver technology verification

0 Design which accommodates TES expansion, void formation and void distribution at micro-gravity without damage.

Screening of conceptual designs for the stirling and Brayton engines was conducted under contract. The cavity heat pipe concepts proposed for the Stirling by Sanders Inc. $(22 \mathrm{~kg} / \mathrm{kWe})$ and for the Brayton by Sundstrand $(23 \mathrm{~kg} / \mathrm{kWe})$ were selected. Both concepts will be evaluated in the critical technology phase, which precedes engineering development, at a $7 \mathrm{kWe}$ level.

In the parallel supporting technology effort, an in-house and contracted technology development program was initiated to screen, identify and select candidate thermal energy storage materials and containment materials through a temperature range of $1100-1400 \mathrm{~K}$. The Lewis in-house program screened candidate materials for parameters such as mass, volume, melting point, heat of fusion, thermal conductivity, specific heat, density and thermal diffusivity. Salts, metals and eutectic TES materials were considered. TES materials and containment material compatibility studies are conducted as part of the Lewis in-house studies. A separate contracted effort with the DOE Oak Ridge National Laboratory (ORNL) evaluates (analytically and experimentally) high temperature TES options. Thermal performance analysis of the TES material is conducted by LeRC in-house and by the University of South Florida. Thermal conductivity enhancement of salt TES materials is being conducted in-house. In addition, to the cavity heat pipe concepts an advanced halogen, direct absorption heat receiver study is being funded with a Lewis Grant at the University of Indiana.

Void formation and void distribution in microgravity was considered a critical technology area affecting structural integrity for the advanced concepts using bulk TES model designs. To resolve this problem a contract was initiated with ORNL to develop a $3-D$ modelling code which predicted void distribution and location under micro-gravity conditions. Code development is completed for $1-\mathrm{g}$ and is nearing completion for micro-gravity. Code verification will be conducted in micro-gravity using a "Get-Away special" flight experiment which is entering the engineering phase. The flight experiment will be conducted as part of the "NASA In-Reach" program. Technology verification is planned first at the component level and then at the subystem level (concentrator and heat receiver) at $1-g$ and space simulated conditions. 
Power Conversion Subsystens

Technology development of the PCS, Stirling or Brayton, is not being conducted at this time in the ASD program. Free Piston stirling engine technology is being carried out in the LeRC Power Technology Division under the NASA CSTI (Civilian Space Technology Initiative) program. It is intended to adopt this technology for ASD as it becomes available and fully developed. Brayton technology is mature and is being pursued in the engineering phase by the Space Station Program and the DOE/AF Dynamic Isotope Power System program (DIPS). This technology will be adapted for the ASD program.

\section{Radiators}

Radiator technology, heat pipe and pumped loop is being carried out in the LeRC Power Technology Division developed under the NASA CSTI program and will be utilized in by the ASD program. This effort includes code development for heat pipes, pumped loops, and advanced radiator concepts.

\section{DISCUSSION}

ASD technology development is directed toward lighter, smaller and more efficient space power systems. However, many critical technology areas exist which must be resolved before an operational ASD space power system is realized. A limited technology base exists for high temperature containment materials and thermal energy storage materials. An example is the lack of reliable data on thermo-physical properties of candidate TES materials (over $1100 \mathrm{~K}$ ). Experimental verification of calculated data is required. The change in volume of TES materials transforming to the liquid phase may create a structural integrity problem (ratcheting) for the design of modular TES containment. Prediction of void formation, void distribution and void size and verffication under micro-gravity conditions is required. Survivability of optical and structural surfaces under the effects of space environment (U. V., atomic oxygen etc.) limits material selection and requires considerable materials evaluation under space-simulated conditions before a selection can be made. This impacts life, fabrication techniques and design. This is being addressed in the ASD program. Resolution of these critical areas requires development of the necessary technology base in materials, analytical tools, fabrication techniques, design approaches, experimental hardware and diagnostic techniques. Development of this new technology base is being implemented at Lewis in in-house programs, JPL, industry and in coordinated efforts with DOE and DOD.

The program is evaluating the efficiency advantage resulting from higher temperature operation. This requires concentration ratios in excess of 2000 and high temperature energy storage materials $(1100 \mathrm{~K}$ to $1400 \mathrm{~K})$. Availability of potential TES material with suitable thermo-physical properties at these higher temperatures is very limited. Availability of containment materials which are compatible with the TES materials is a critical issue. It is not known if operation at these high temperatures. $1300 \mathrm{~K}-1400 \mathrm{~K}$, is feasible because of potential containment and fabrication problems. This may be a limiting factor as well as limits imposed on operational temperatures and system efficiency due to the reradiation problem from the heat receiver aperture. Very accurate concentrator/receiver alignment is required for high temperature operation. These areas are under evaluation to determine the upper temperature limits for an Advanced Solar Dynamic Space power system.

Technology verification at the system level is planned; however, this is contingent on availability of funding. 


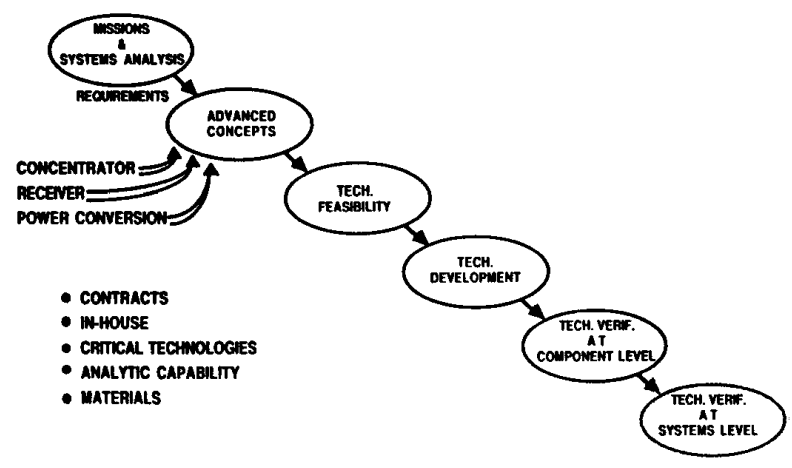

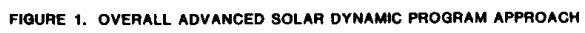
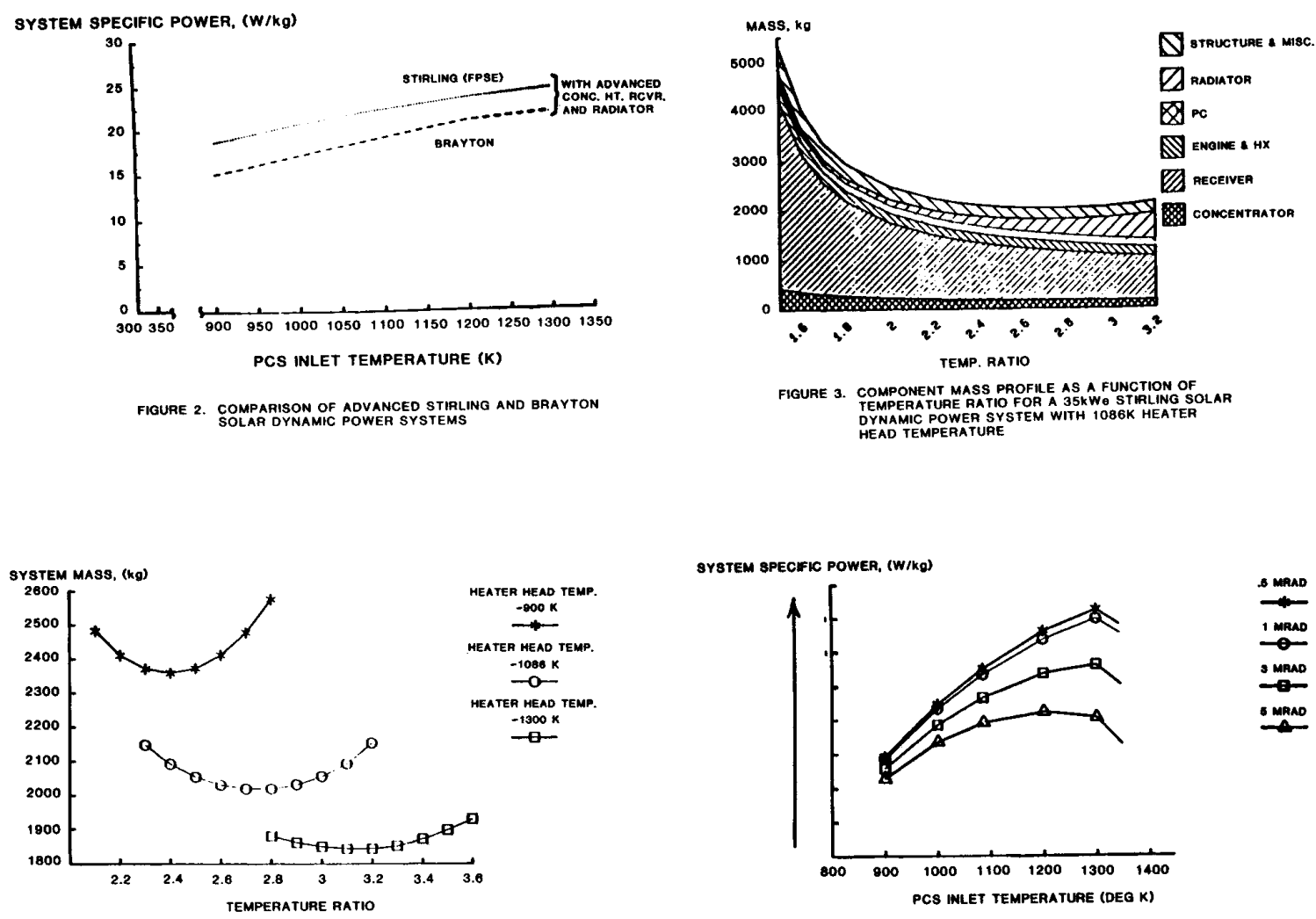

FIGUAE 4. SYSTEM MASS SENSITIVITY TO TEMPERATURE RATIO FOR A HEATER HEAD TEMPERATURES

FHQURE 6. EFFECT OF CONCENTRATOR SLOPE ERROP ON AN AOVANCED

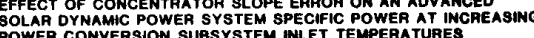

